\title{
Using Cognitive Neuroscience Principles to Design Efficient Reading Programs: Case Studies from India and Malawi
}

\section{Cognitive Neuroscience to Design Literacy Programs}

\author{
Radhika Iyengar \\ Correspondence: Radhika Iyengar, Earth Institute, Columbia University, USA.
}

Received: March 18, 2019

doi:10.11114/ijce.v2i2.4394
Accepted: April 11, $2019 \quad$ Online Published: July 21, 2019

URL: https://doi.org/10.11114/ijce.v2i2.4394

\begin{abstract}
The hidden crisis in education has come to light since the past decade. Millions of school-going children remain illiterate, even after spending 2-3 years in school. This paper explores a cognitive neuroscience driven method to improve children's reading in two local languages--Chichewa (Malawi) and Telugu (Telangana, India). The paper first presents the science behind how children learn using this science-driven model. It then presents the process of contextualization of this literacy method for Malawi and Telangana, India. The contextualization and adaptation processes lead to some generalized principles that could be applied to other local language literacy programs. The study looks at sequencing of letters, font size and type, teacher training modalities as well as classroom delivery processes, which are all key components for any early literacy intervention. The study also focuses on cost-cutting measures to aid in full implementation and scale-up for a low resourced educational setting.
\end{abstract}

Keywords: cognitive-neuroscience, literacy, local language, India, Malawi

\section{Introduction}

Over the course of the past decade, the education discourse has been centered on learning. The reality that schooling does not equate to learning has been a relatively recent discovery. The Sustainable Development Goals (SDGs) place "quality education" front and center in the Education Goal. Therefore, this invisible crisis cannot be overlooked anymore. The Millennium Development Goals (MDGs) focused on access to primary education with less attention given to quality, and, as a result, "many of the children in schools are receiving an education of such abysmal quality that they are learning very little" and therefore unable to advance to higher levels of education and employment (p.13, UNESCO, 2013). Two hundred fifty million young people are unable to read, write, or do basic math, with 130 million of them already enrolled in school (UNESCO, 2014). Unfortunately, this learning crisis is not limited to only a handful of countries (Beatty and Pritchett, 2012).

Recent trends on learning show that more than 50 percent of grade 2 students in Malawi, India, Ghana, Uganda, and Zambia cannot read a single word of a short text (World Development Report, 2018). More than 50 percent of current grade 2 students cannot perform two-digit subtraction in India, Uganda, Ghana, Nicaragua, Iraq and Kenya (World Development Report, 2018). These disturbing trends are not new findings. For over ten years, learning levels have showed a dismal record for many countries across continents.

The reasons for schools failing their standards of learning has been well-studied and is broken down into the following pockets: (a) lack of teacher preparation, (b) lack of accountability on the part of the schools and (c) that students who are academically week are usually coming from economically weaker backgrounds and thus need a lot of support, and schools are unequipped to provide a quality learning environment. Some groups of people blame it on systemic and policy issues relating to funding. While teacher preparation, accountability, socio-economic background of students form the foundations of a supportive learning environment, they do not address the core issue of how children learn.

The purpose of this study was to integrate the cognitive-neuroscience based reading approach in these geographic areas (Malawi and Telangana). The approach had already shown improvement in literacy rates in The Gambia (Abadzi, 2006). Therefore, rather than proving its effectiveness, this study attempts to present contextual factors and outcomes as a result of the contextualization. This study attempts to unpack the components of a cognitive-neuroscience based pedagogy that has improved early grade literacy rates in The Gambia and Egypt. This study looks at contextualization of this reading 
approach in the case of Malawi and India. The adaptation and implementation processes that are followed to implement this cognitive-neuroscience based theory could be generalized to other settings to improve local language literacy. The objective of this paper is to highlight these site-specific nuances to be able to draw generalized principles that have the potential to aid early literacy interventions. More specifically, the main research question this study addresses is, what are some of the key components of an early literacy program that need to take into account contextual and site specific differences? How can a cognitive- neuroscience based learning model be applied in a low resourced setting? Therefore, which implementation research findings can be generalized and applied to other early learning initiatives?

Measuring the status of learning for school-going age children was traditionally done by end of the year examinations. The performance of children in these examinations was traditionally limited to the teachers. That is, only teachers who assessed these children knew whether they could actually read, write and do math. In many countries, children in primary grades have "automatic promotion" policies, whereby, irrespective of whether the children is progressing in learning, s/he is promoted to the next grade. It was traditionally thought that parents in many countries were illiterate and could not understand their children's learning levels, so they would be kept out of the loop. While these summative learning assessments or end of the year exams still continue, formative assessments throughout the year to course-correct the learning gaps have been included in national curricular frameworks more recently. Another paradigm shift has been moving away from an input-based approach to an outcome-driven approach. This essentially means student outcomes are being prioritized rather than measuring whether schools are equipped with inputs such as desks, benches, etc. It was observed that, even if schools have all the inputs, they are still unable to improve students' learning levels. In the international education discourse, there are some stakeholders who blame teachers for their poor quality training, while there are others blame the curriculum, which they see as overly ambitious. Some groups blame the lack of accountability amongst the school management to improve learning outcomes, while others blame the lack of adequate reading level on the lack of funds for the Education Sector.

Table 1. Children by grade and reading level (2016)

\begin{tabular}{lllllll}
\hline Grade & $\begin{array}{l}\text { Not even } \\
\text { letter }\end{array}$ & Letter & Word & $\begin{array}{l}\text { Grade 1 level } \\
\text { text }\end{array}$ & $\begin{array}{l}\text { Grade } 2 \\
\text { level text }\end{array}$ & Total \\
\hline 1 & 46.1 & 31.7 & 12.4 & 5.0 & 4.8 & 100 \\
2 & 23.5 & 31.5 & 19.8 & 11.8 & 13.4 & 100 \\
3 & 13.6 & 24.1 & 19.9 & 17.3 & 25.1 & 100 \\
4 & 8.5 & 17.2 & 17.7 & 19.2 & 37.4 & 100 \\
5 & 6.0 & 13.3 & 14.2 & 18.6 & 47.8 & 100 \\
6 & 4.0 & 9.6 & 11.6 & 18.0 & 56.9 & 100 \\
7 & 2.8 & 7.2 & 8.9 & 15.1 & 66.1 & 100 \\
8 & 2.0 & 5.4 & 6.5 & 13.0 & 73.0 & 100 \\
\hline
\end{tabular}

Source: Annual Status of Education Report 2016.

http://img.asercentre.org/docs/Publications/ASER\%20Reports/ASER\%202016/4\%20pagers/enrollmentandlearningrepo rtcard_english.pdf

The ASER 2016 report on rural India suggests a grim picture on learning levels. Only about 50\% of children in grade 5 are able to read a grade 2 level text. There are about $8 \%$ who are unable to read anything and are currently in grade 4 . There are only $12 \%$ of grade 2 students who are able to read a grade 1 level text. A study conducted in 2014 in the Medak district, Telangana, revealed lagged learning as well (Columbia Global Center, Mumbai, 2014). A total of 79 students were assessed using the ASER India tests in Telugu. The results revealed that, by Grade 3, all students were able to identify all the letters of the Telugu alphabet, and as they progressed to higher grades, the number of students who could read words, sentences and stories increased, however the number of students who understood the meaning of these words and sentences was minimal. By Grade 5, the situation was better, but around $80 \%$ of students still could not understand Grade 2 level sentences. By Grades 4 and 5, all children should be able to read Telugu fluently and understand the meaning of words and sentences because they are all at a Grade 2 level text.

The Early Grade Literacy Assessment (EGRA) results for Malawi 2012 also show that students are not learning to read in the first year of primary school and incrementally learn very little over the next two years (Pouezevara \& Odala Banda; 2012). The report noted that students in Grade 4 are able to read 15 words per minute, which is far below the 45 words per minute benchmark. Therefore, the lag in learning levels starts from Grade 1 and continues onwards. In many countries, the official approved language in the school is different from the local dialect. For instance, in Ghana, only twelve 
languages are approved regionally whereas there are hundreds of local dialects spoken. Many of these languages do not have a written script. Therefore, children enter Grade 1 in these schools and are taught in a language not spoken at home. In countries that have official languages at school that are different from students' home languages, learning gaps start from Grade 1. However, in countries like Malawi, where there is only one local language, Chichewa, which is also the language of instruction at school, learning gaps still exist.

\section{Literature Review on How Children Learn}

This section explores the literature on learning approaches that have been widely discussed in educational discourse and have relevance to the India and Malawi case studies. Given below are not mutually exclusive categories showing how children learn, but they are discussed separately since these components are critical in shaping early learning pedagogies. These sections are divided between learning approaches starting with using constructivist theories, Pratham's Teaching at the Right Level, whole language versus phonics based, and teaching transparent orthographies. The sections detail out the method and discusses their approaches.

The first of learning to read approach is the student-centered learning approach. This approach leans more towards constructivist theory, which emphasizes that the student is driving the learning process (Baeten, Kyndt, Struyven., \& Dochy, 2010; O’Neill, Gerald \& McMaho, 2005). The student actively participates in the learning process. In this genre, many teaching methods were developed, such as problem-based learning, project-based learning, student-activating teaching method, and collaborative/cooperative learning (Baeten, Kyndt, Struyven., Dochy, 2010). This method criticizes the role of the teacher as information giver; rather, the teacher acts as a facilitator and collator of knowledge (O'Neill, Gerald \& McMaho, 2005). The teacher needs to be able to assess student needs and guide students through the process of learning. This method, although student-friendly, becomes difficult to administer in large classes. In rural parts of Africa and India, due to the large enrollment drives, class sizes vary from 40 to 70 and could be even greater. Usually, these children are managed by one or two teachers in one space; students come from different grades and are at different learning levels. In these circumstances, the teacher will not be able to attend to each student's individual needs.

Pratham's Teaching at the Right Level has been extensively evaluated in various contexts (Banerjee, Banerji, Berry, Duflo, Kannan, Mukerji, \& Shotland, and Walton, 2016). The author notes that Teaching at the Right Level helps children who are falling behind grade level learning expectation in grades $3-5$. The method includes a simple assessment. Groups are made based on the assessment results. The method uses learning material that is appropriate to the level of the kids in the group. This approach has many elements in common with the pedagogy of this paper. First, it uses barakhadi, which is a chart of individual letters. Children are asked to recognize the letters with the sounds. Secondly, the approach uses a large font size and small sentences when the children are at the early reading level. Focus is given to students' daily practice of recognizing letters and their sounds, which is very similar to the approach used for this paper.

There is a long debate on whole language learning versus the phonics method, which is worthwhile to mention here. The whole language learning approach is where the language is situated in a familiar context so students can utilize familiar knowledge about their immediate environment and use this towards learning the language. The idea is that learning is highly contextual, so for students to be able to learn, the "whole" experience needs to be offered. This is a more comprehensive holistic philosophy of learning. It emphasizes "literature, composition, inquiry and process-centered instruction" (Dahl \& Schare (2000, p. 584). The whole language approach focuses on meaning making in context. There is a long, ongoing debate between the whole language learning approach and the phonics method. The phonics method essentially helps to recognize letters and attach them to a sound. This method ensures that students are able to learn through symbol-sound recognition. This method may mean that students are able to decode the letters and, with added letters, learn to form words. This approach is more about learning to read rather than attempting to learn a language. Here, students may not know the meaning of the words, however they can read them through this decoding process. Bauman, Hoffman, Moon, \& Duffy-Hester (1998) conducted a survey of U.S. teachers on phonics versus the whole language learning approach and cited pros and cons of each. The authors cite other researchers, who state that the whole language approach may have shown a decline in reading achievement as opposed to the phonics method, which has systemic and direct instructions for students. Bauman, Hoffman, Moon, \& Duffy-Hester's (1998) teacher survey illustrated that the majority of teachers in the U.S. use a balanced, eclectic approach to elementary reading instructions. They blend phonics and whole language approaches in "compatible ways" (p. 640). The result is very similar to Dahl \& Scharer's (2000) conclusion that these two methods are not mutually exclusive and can be blended together in meaningful ways.

Since 2011, a number of experimental reading methods have been financed. Many previous literacy-focused studies, examples include the HALI (Health And Literacy Intervention) and Aga Khan projects of Kenya (e.g., Jukes et al, 2014), have shown modest outcomes. In contrast, pilots of the reading method described in this study in Gambia and Egypt have shown promising improvements in letter recognition. This study uses cognitive neuroscience principles to improve reading by continued practice and corrective feedback from teachers. This helps students reduce the reaction time of 
recognizing letters, thus increasing their reading speed. Speed has a high correlation with comprehension (Pirolli \& Anderson, 1985).

This reading method does not apply to French or English. It is best applied to transparent orthographies, which are languages that are consistently spelled. The method takes the readers from learning smaller chunks to learning bigger chunks of words. This simple method means that children learn letter by letter, trying to attach a sound to the letter. The letter appears as a face to the children. With practice, they are able to join letters to other letters and form words, and they are able to read these larger chunks, which require substantial practice in reading (Abadzi 2013b). The teacher helps to decode the letters and their sounds and then provides corrective feedback rather than lecturing using the board. Children are required to do individual practice by keeping their fingers on the texts while the teacher provides them corrective feedback. Due to working memory limitations, students must retain a minimum reading speed, which helps in understanding the text. No extra activities are provided for comprehension.

Unlike English, mere knowledge of letter sounds and practice in composing them reliably evokes Telugu words (Seymour et al, 2003). In addition, visual factors matter: letter spacing and fonts must be optimized, as suggested by USAID-sponsored research (DeJongh, 2014). A method combining these elements should teach fluent and effortless reading to nearly all children. This method works with large classes, since the teacher is expected to teach using the book for 10 minutes of the class; the rest of the time, the teacher acts as a facilitator and provides corrective feedback to students. The method also works best with students who are at the letter recognition level. The method is cognizant of the fact that teachers may not be highly trained in these circumstances and may suffer from working memory overload (Feldon, 2007). Therefore, minimal training is required to reduce the financial costs and improve teacher instruction with easy steps for them to follow.

Cognitive neuroscience research suggests that initial learning days are critical for students and a lot of attention needs to be given to children. Children must first understand that each letter/symbol has a sound associated with it. Many students may have a problem differentiating between two symbols/letters (Franceschini et al. 2012; Marinelli et al. 2012). Therefore, varying sizes must be provided to make the distinction clear. Cognitive neuroscience research suggests a "traditional" method that focuses on a lot of repetition and practice is the most efficient way for students to learn how to read. In India and in other places, a very similar approach of using the varnamala, or the letters in a certain sequence, was repeated many times in classes. This approach was stopped in most states in India, which was followed by the advent of the whole language learning approach. The whole language approach was a western concept, which was adapted willynilly in India and elsewhere. The concept assumed certain exposure to books and language before the child enters grade 1. This was not a reasonable assumption since, in most rural areas, story-books and textbooks at homes for kindergarteners are still a rarity. Therefore, the science of learning from smaller chunks to bigger chunks using the barakhadi charts was replaced by a teacher facilitated discussion on the students immediate environment, reading poems and jumping into a writing exercise--the writing component became a drawing exercise for most students. This study helps to understand the adaptation of this cognitive neuroscience approach to support efficient student learning in the case of Chichewa, Malawi and Telugu, India.

\section{Application of the Cognitive-Neuroscience Based Research}

The application of this cognitive-neuroscience based literacy approach is rather simple. The teachers have to follow five simple steps in the classrooms. First, the teachers need to demonstrate the letters to the entire class. They need to put their finger on the letter in the workbook/exercise book, which has been specifically created for these literacy classes. The teacher reads the letter aloud and clearly. Second, the teacher shows a combination of the letter with other letters and again, clearly and loudly, reads out the letter combination. The students do not repeat the teacher, but carefully listen to how the teacher is pronouncing the letters and the shapes associated the letter. Third, the teacher ensures that all children are paying attention to the letter pointed out in the exercise book. The teacher goes around the class pointing to the letter and showing it to all the children. Fourth, the students now look at their individual workbooks and point to the letter and practice reading it aloud; this part should take up the majority of time in the lesson. Fifth, the teacher goes to each student to provide any corrective feedback required. The teacher sees where the child is pointing and listens carefully to the pronunciation of the letters.

This simple routine does not require extensive teacher training preparation, nor does it require small class sizes. This routine could easily be done with 60 plus class sizes, which are a reality in most rural parts of Malawi, India and other countries. One letter a day is introduced initially. This is followed by combinations of letters to make words that do not make sense; soon after, teachers transition to meaning-making words, as more letters are covered. The letters vary in size, which helps the brain register their shapes more efficiently. The order of the letters is not in the traditional alphabetic order, but in the frequency that it occurs in a typical grade 4 textbook. The frequency of the letters is recorded by taking 3-4 
pages of a primary school text (about 1,000 words). If the language has lower-case and capitals, the capital list is covered at the end to avoid confusion.

The teacher focuses on the letter, which is slowly introduced (1 letter introduced in 1-2 days). Letter sounds are pronounced carefully, making sure that each student understands the symbol/letter along with the sound associated with it. Slowly, these letters are added to other letters and bigger chunks are formed that range from two to four letters. These combinations of letters slowly start to become sentences. By this time, the complexity of words has increased and students should have knowledge of most of the letters.

In around 100 days, children are able to decode words and read sentences. Practice of about 2 hours is required everyday to reach this goal. Teacher training focuses on how to distribute class time. The class is divided into "I do," "we do" and "you do" time. This includes 10 minutes of teacher instruction time to demonstrate the letter and the associated sound. The "we do" time is when students repeat what the teacher just showed, along with the teacher; this is around 15 minutes. "You do" time is when students do individual practice. In training sessions, teachers are asked to involve everyone and provide corrective feedback to all/any student(s), since it is well-researched that teachers often pay attention to selected students and the students respond by being more responsive than others who are neglected (Lockheed and Harris, 2005).

The approach does not involve additional development and use of Teaching Learning Materials (TLM), such as Flash Cards, etc. The only teaching aid that teachers have is the same workbook that each student has. This helps to cut down on additional TLM costs as well as reduce the instructions for teachers during the time of teacher training. The workbooks are carefully crafted and piloted before actual interventions. Inputs from various experts, including linguists, TLM and textbook developers, teachers, and Government school monitors, are incorporated to finalize the workbook content. The size of the letters should be big enough for students to put their fingers on and be able to move to the next letter. Adequate spacing between the letters should make it easier for the students to distinguish between the letters; this will help the letters register into childrens' memories with only a few tries (e.g. Arai et al. 2009).

\section{Results from the Reading Approach in India and Malawi}

The learning program in Malawi ran from 2014 to 2015 and was followed by the India program from 2016 to 2017. A random selection of control and treatment groups were created (sample details below, per pilot). Since all the conditions were the same for all classes, the assumption was that the control and treatment groups would have similar characteristics. It is important to note that the same children were not tested in the baseline and the endline. Children were randomly sampled from the classes for the baseline and the endline and thus, the same children may or may not be included in these two assessment. However, the same classes with the same teachers were included in both assessments. In both cases, classes were physically located in a small geographic location and thus catered to groups of students who were similar in terms of their background characteristics and school and teacher characteristics. Student background and school level characteristics were not collected. The intention was to implement a tried and tested pedagogy with appropriate contextual adaptations and not to evaluate the effectiveness of this intervention.

\section{Assessment Test}

Four sub-tests of the Early Grade Reading Assessment (EGRA) in Chichewa were adapted to assess the children at baseline and endline. USAID and the Ministry of Education implemented EGRA at the national level. The four subsets took more than 10 minutes to assess each child. The subtests included a measurement of student knowledge of letter names, letter sounds, familiar words, oral reading fluency and reading comprehension in a series of timed tests. Knowledge of letter sounds, reading fluency and comprehension were measured from baseline to endline (author, 2016). A similar approach was used to develop tests for Telugu in India.

\section{Telangana, India}

The Jagdevpur block of Telangana State includes 41 schools in 4 geographic subgroups called Complexes. Complexes are government-mandated groups intended to ensure administrative convenience to conduct educational trainings and facilitate services linked to schools. Out of the 41 schools, 30 schools were chosen to collect the data based on high enrolment numbers in early grades. Around $10 \%$ of the enrolled students in grades 1, 2 and 3 were administered the Telugu literacy test. Test data was collected for a total of 252 students.

\section{Mwandama, Malawi}

The Millennium Village (MV) ${ }^{1}$ cluster of Mwandama had a village-learning center (VLC) program ${ }^{2}$ run by a group of 27 volunteer community education workers (CEWs). These VLCs ran in the community after school hours. They were

\footnotetext{
${ }^{1}$ Read more about the Millennium Villages here. http://millenniumvillages.org

${ }^{2}$ http://cgsd.columbia.edu/2013/07/16/addressing-the-global-learning-crisis-the-case-of-mvp/
} 
initially planned to help students with their school homework. But soon, the Millennium Villages team realized that children were falling behind their grade level learning: students needed help to attain basic literacy rather than assistance with their homework. These classes ran in community spaces, such as churches and houses. Twenty-nine CEWs taught in VLC classes, with an approximate enrolment size of 1,125 children total. The project intervention has been rolled out to 27 of the VLCs, with the exception of 2, which were kept as control groups. Baseline data was collected from a sample of 112 students from five of the VLCs (author, 2016).

\section{Malawi results}

Detailed account of the Malawi results have been published by author (2016). For the purposes of this paper, only comparative results with Telangana are included. The key comparative indicators include fluency and accuracy for letters. The benchmark for fluency is taken to be 46 words per minute (see author, 2016 for details).

\section{Letter Fluency and Accuracy}

Figures 1 and 2 suggest there was a lot of improvement in the letter sound recognition in the treatment group versus the control group. The treatment students knew almost 13 more letter sounds per minute than did the control group. Treatment group students also were more accurate in their knowledge of letter sounds, with an average of $62 \%$ correct by endline (author, 2016). Since the focus of the reading approach was to emphasize letter symbol and sound recognition, there was a lot of improvement in this category. Comparison by grade shows that, as compared to all the grades, Grade 1 students improved by only 19 percent. Therefore, the literacy program should give more emphasis to improving letter fluency and accuracy rates for Grade 1 students.

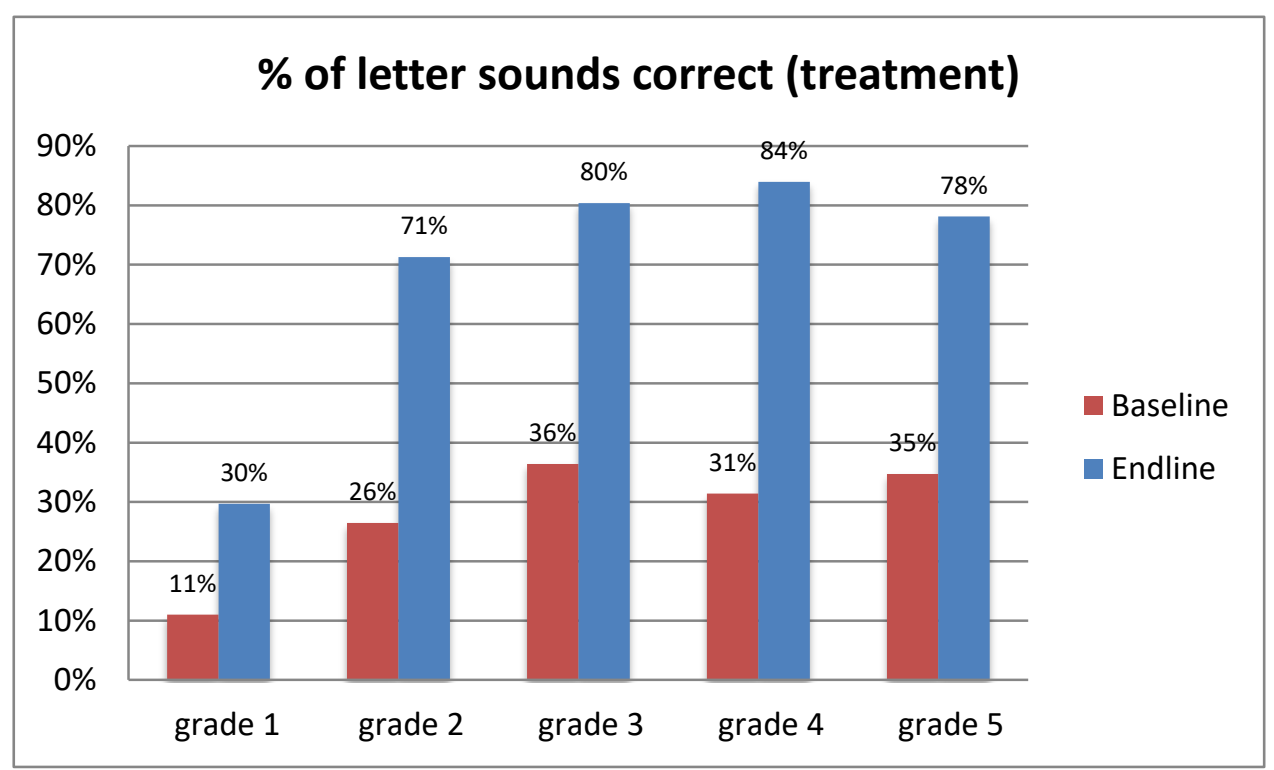

Figure 1. Percentage of correct Letter sounds for the treatment group for Malawi

Source: author (2016). 


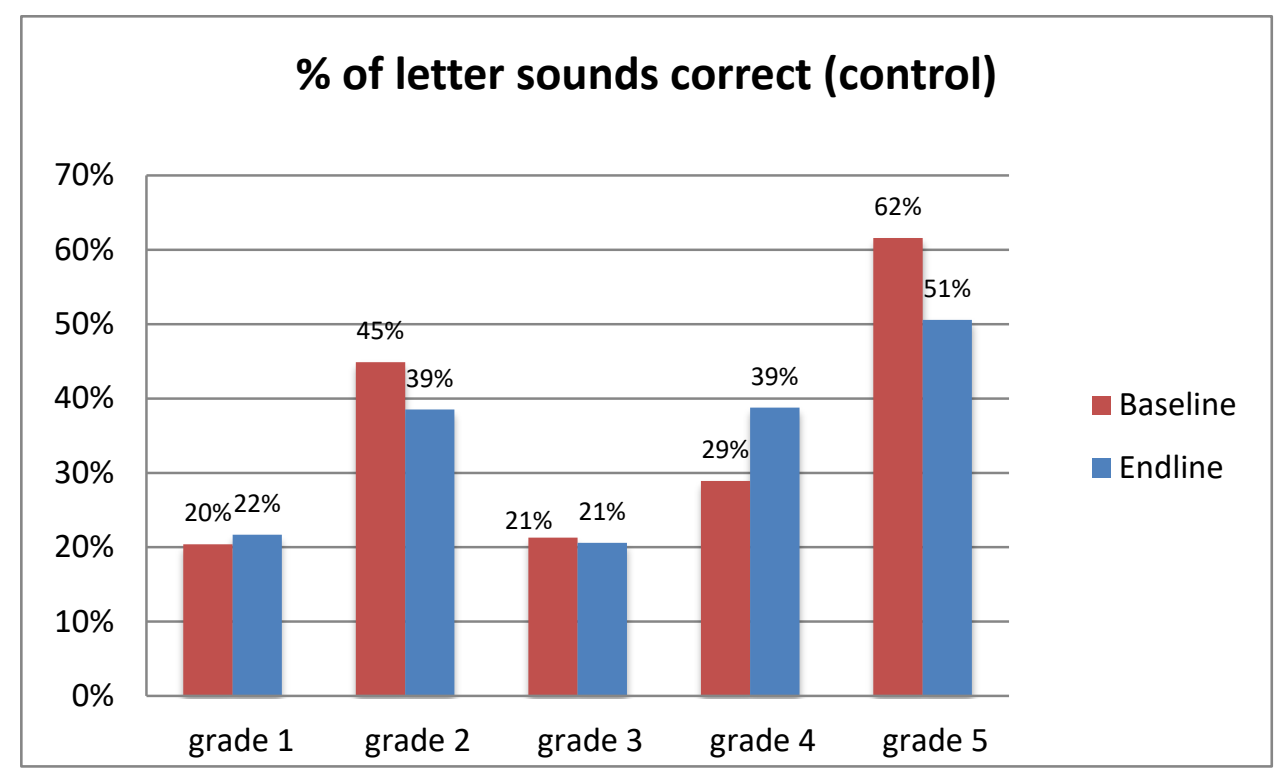

Figure 2. Percentage of correct Letter sounds for the control group for Malawi

Source: author (2016).

\section{Words Fluency}

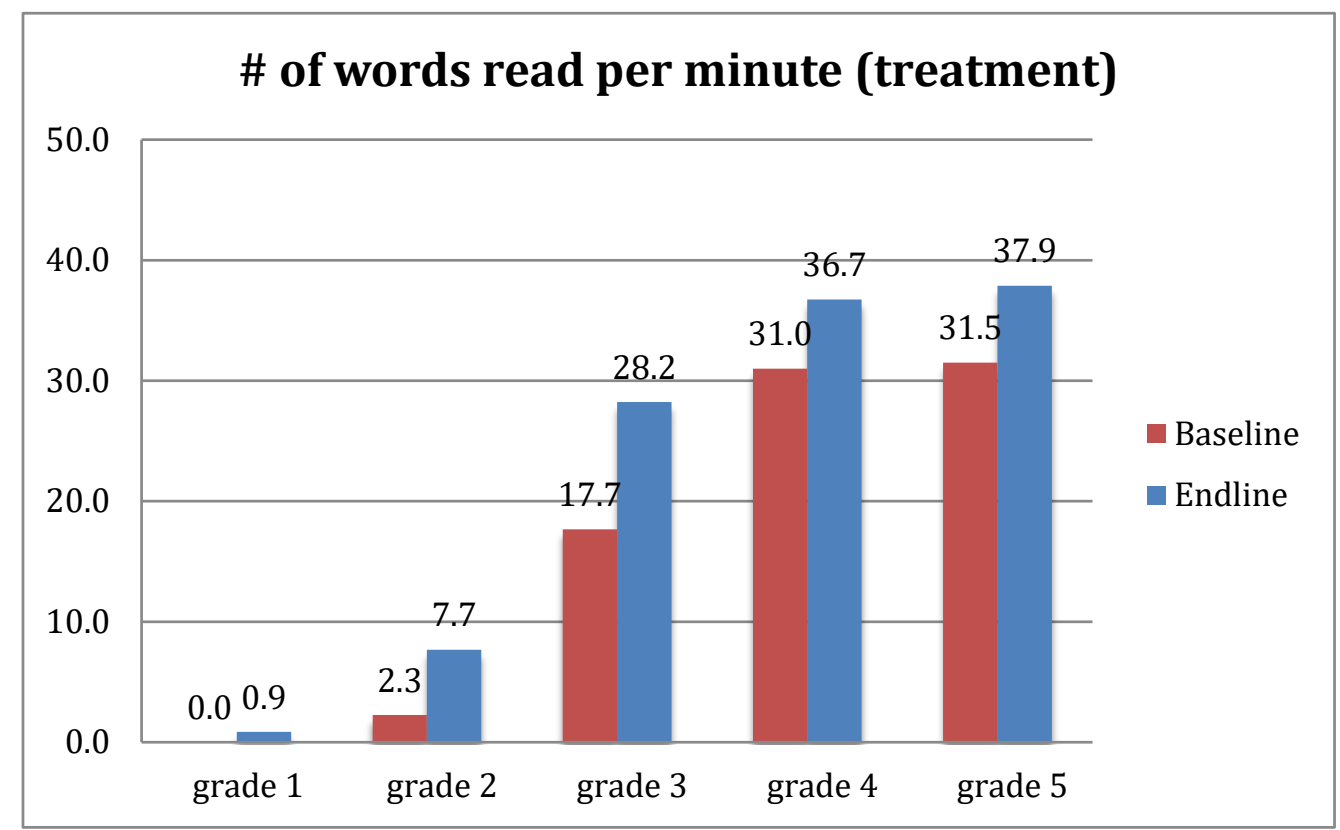

Figure 3. Words read per minute for the treatment group for Malawi

Source: author (2016). 


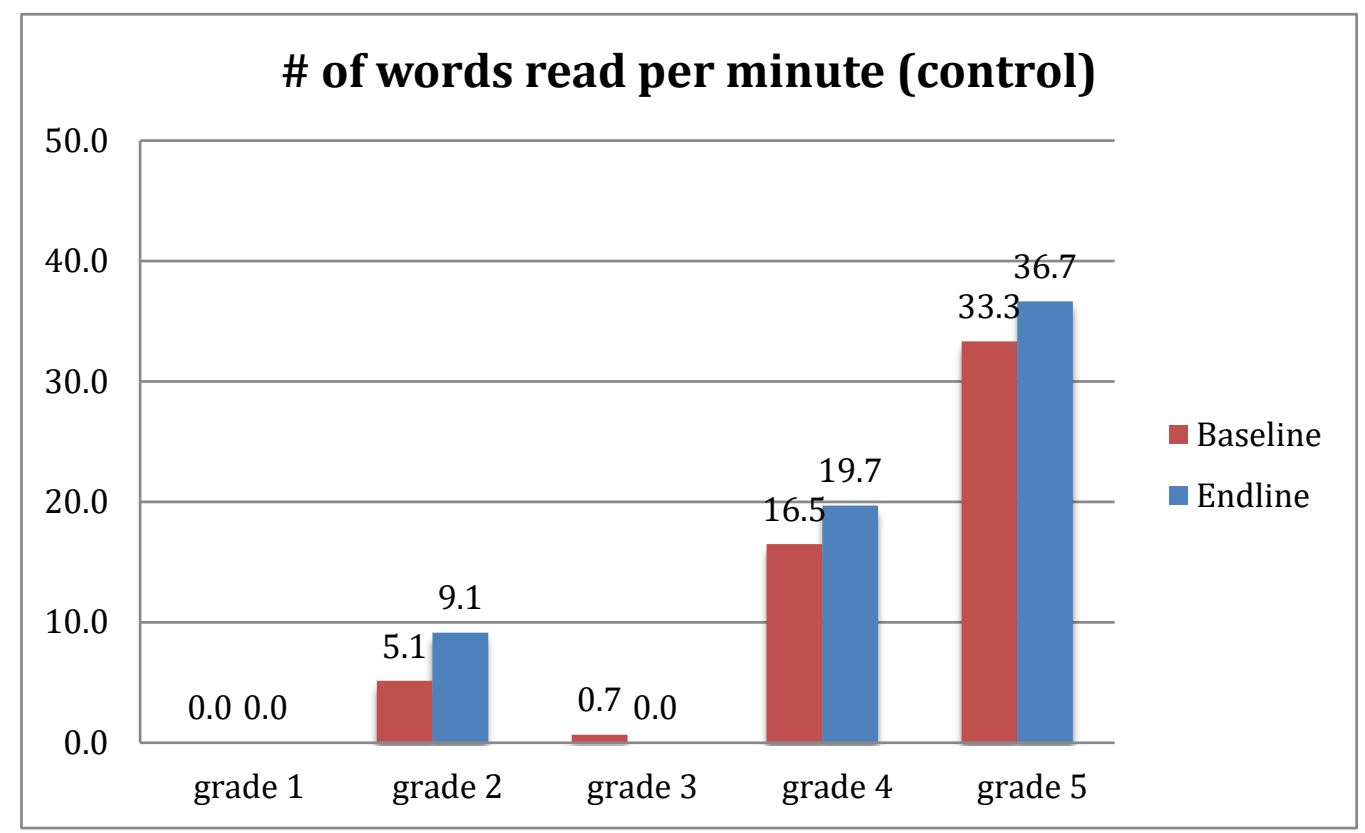

Figure 4: Words per minute for the control group for Malawi

Source: author (2016).

Fluency in reading words also showed an improvement in the Treatment group as compared to the counterpart, although the fluency rates for words were nowhere close to 46 words per minute. This showed the program needed more time in its implementation to meet the benchmark. For every grade, the increase in the treatment group was higher than the counterpart group.

\section{Word Accuracy}

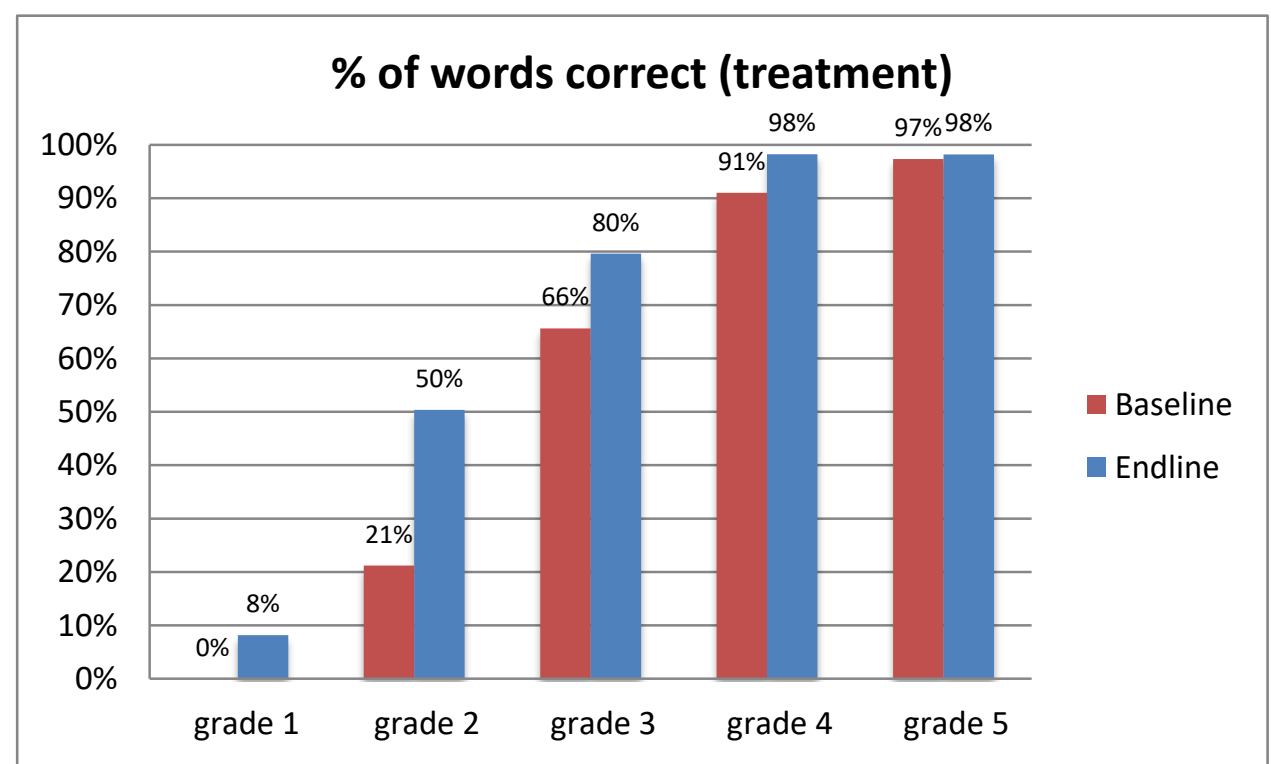

Figure 5. Accuracy for words in the treatment group in Malawi

Source: author (2016). 


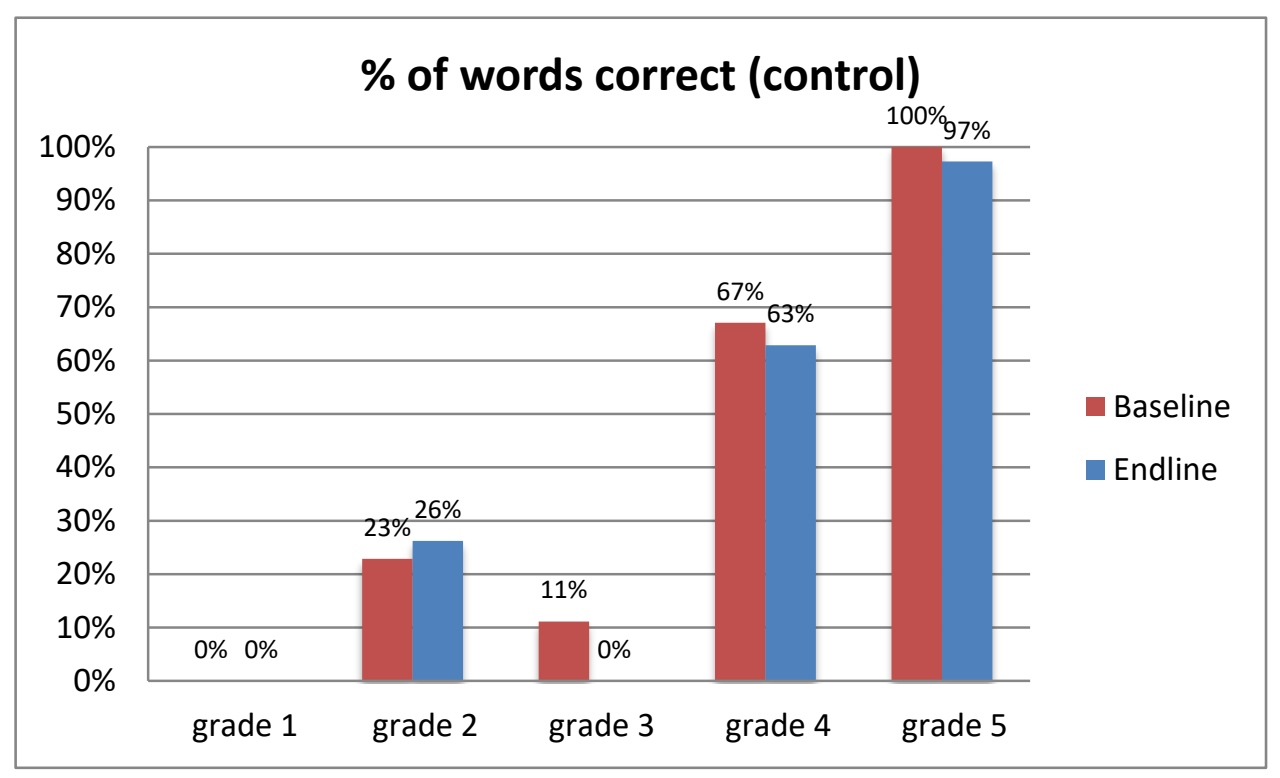

Figure 6. Accuracy for words in the control group in Malawi

Source: Author (2016).

Students in the treatment group read words more accurately than their counterparts. However, by grade 5, this difference mitigated. This is again proof to show that the literacy approach is best with early grades. Grades 1 and 2 showed more improvement than grades 4 and 5 .

\section{Telangana results}

\section{Accuracy}

Accuracy in the syllabic scripts is a significant problem. Particularly in the southern scripts, children kept making mistakes throughout primary school. The data shows that in the treatment group, students overall read $70 \%$ of words correctly compared to only $20 \%$ of the words read correctly in the control group. Percentages were even higher for letters. As expected, children in higher grades were reading more accurately than children in lower grades (Figures 7 and 8).

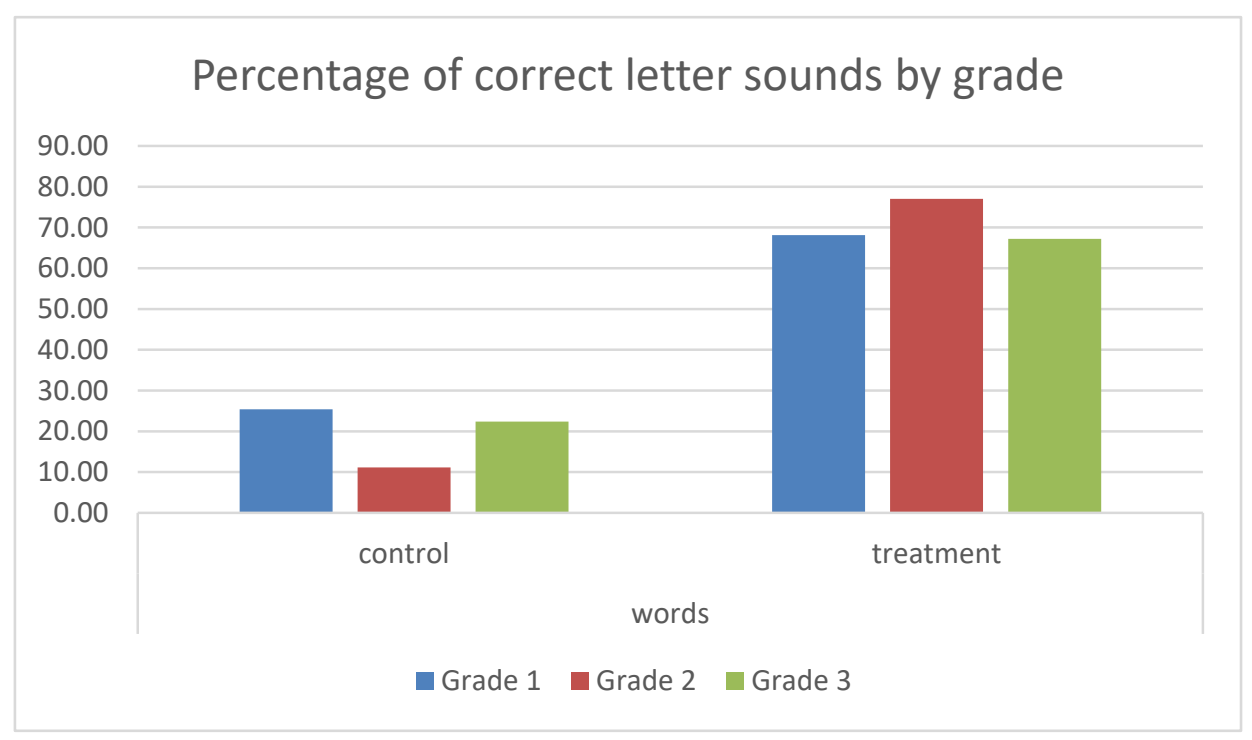

Figure 7. Percentage of correct letter sounds by grade 


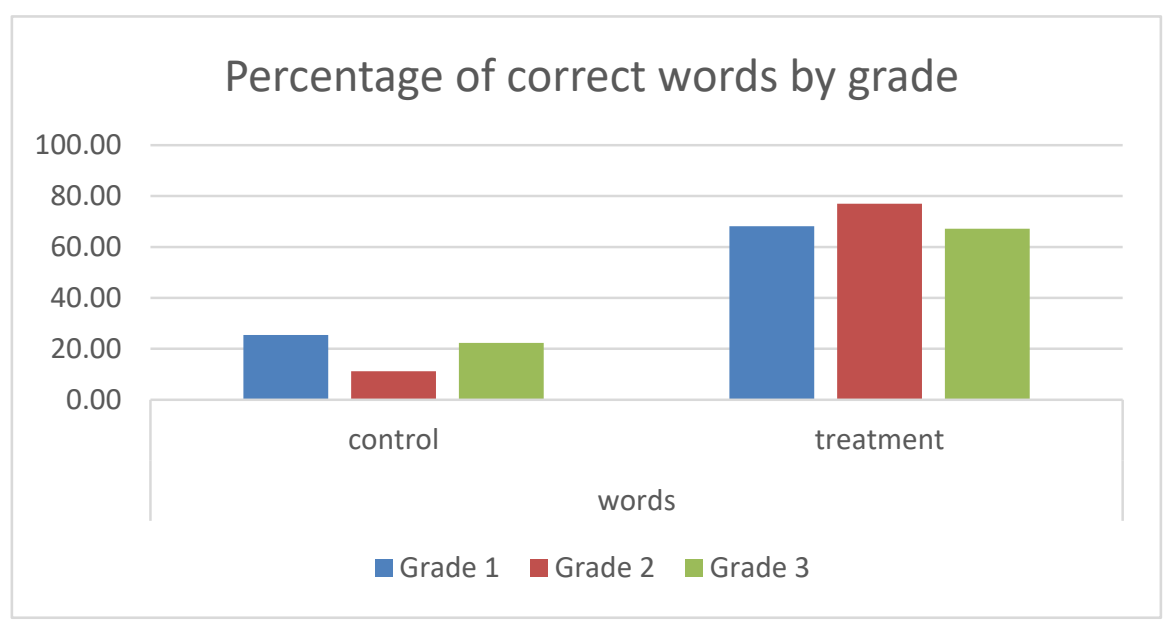

Figure 8 . Percentage of correct words by grade

\section{Fluency, Words Per Minute}

Students' reading speed remained lower than needed for effortless reading, due to limited practice time. On average, first graders read 8 words per minute in the treatment group as compared to about 3 words per minute in the control group. Nevertheless, the treatment group surpassed the control group by $280 \%$ to $569 \%$ in words, syllables or letters read per minute (Figure 8).

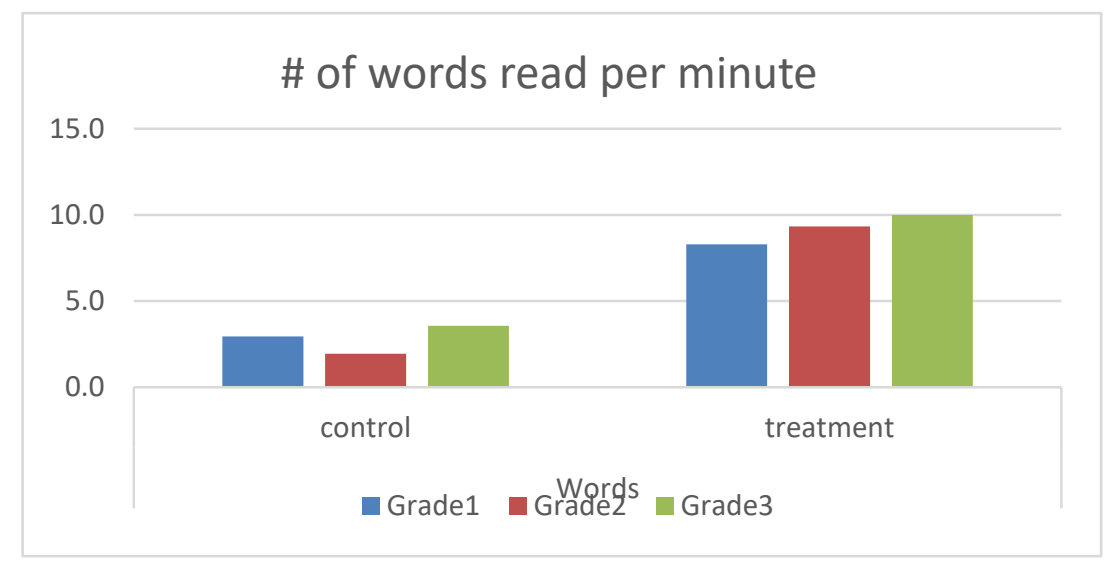

Figure 8. Fluency mean is the number of words read correctly per minute

\section{Children Unable to Read}

The method drastically reduced the number of students reading zero words (children who could not read at all; missed the first row of letters; missed the first row of syllables; or missed the first row of words). Overall, in the treatment group, more than $71 \%$ of children across grades could read, compared to only $15 \%$ in the control group (Figure 9).

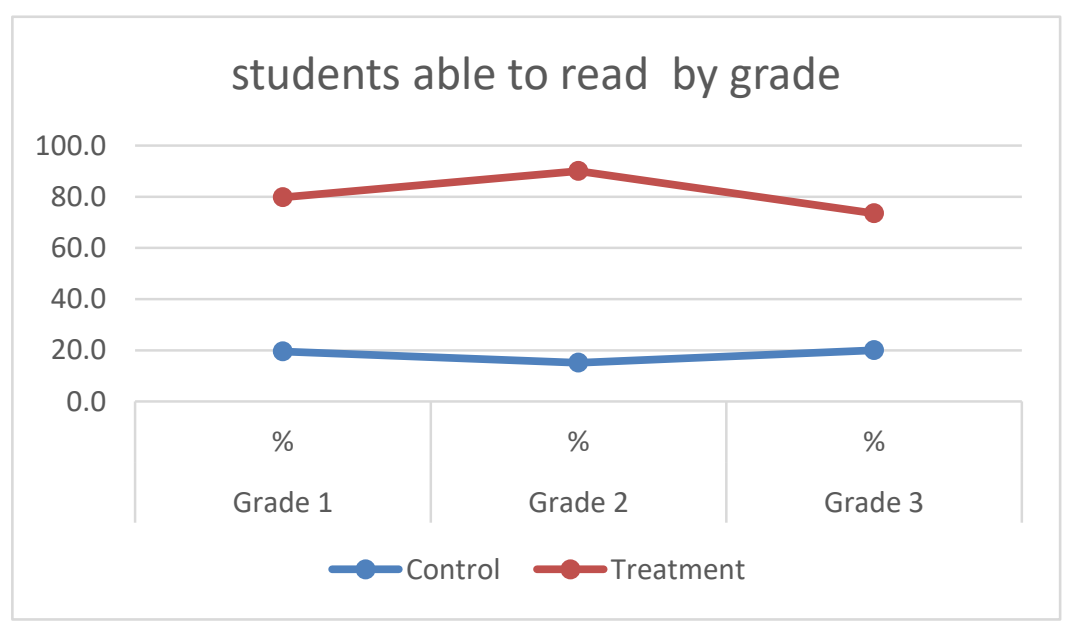

Figure 9. Percentage of students able to read 
The teachers had very good comments about the method and most expressed the desire to use it again. After this first pilot, the textbook will be improved on the basis of teacher suggestions. The district government is actively seeking funds to scale-up the literacy pilot in the district. These experiences suggest this reading method can be used efficiently to improve literacy levels in early grades.

\section{Study Data}

The data for this study comes from program-related documentation and meeting notes from Malawi and India. Contextualizing the literacy approach in Malawi and India required meeting multiple stakeholders, including linguists, cognitive-neuroscientists, district government officials, teacher trainers, school monitoring officials, etc. Stakeholders met at workshops to discuss the literacy approach and its adaptation for Telangana. This discussion formed the bulk of the data for this paper. Secondly, observation of teacher training and teacher feedback formed an important part of the data for this study because it helped with highlighting the contextual factors. Third, classroom observations helped to assess the adaptation of the literacy approach. For instance, vowels in Telugu took another shape when added to letters. Therefore, the sequencing of these letter-vowel combinations was critical. Classroom observations helped to see the progress that children were making with these combinations of letters. This helped to understand if the sequencing of the letters needed adjustments. Fourth, interviews with teachers who implemented this method in class helped to fine-tune the local adaptation based on their feedback.

\section{Contextualization and Adaptation}

Contextualization and adaptation of the cognitive-neuroscience based model forms the basis of this paper. This section pertains to implementation research that was required to translate a theoretical learning approach to a practically applied literacy approach.

\section{Mwandama, Malawi}

The workbook, "Bukhu Lothandizira Kuwerenga," was developed in conjunction with the government's Primary Education Advisor (PEA) in the district (author, 2016). The workbook consisted of 30 chapters, wherein each chapter introduced a new letter. There is also a review after the completion of four new letters. Each chapter is roughly four pages long. The letter is the largest size when it is introduced and then varies in the consequent pages. Chichewa sounds are most commonly taught through syllables, with a consonant preceding a vowel.

Some words in Chichewa are very long or agglutinative words. These words have prefixes and suffixes, making the word length really long. These agglutinative words were broken down into smaller words for new readers to read. In earlier chapters, meaningless words were taught, since only a few letters were introduced early on. With the addition of more letters, more words with meaning could be created. It was merely to give practice to students and a sense that each letter has a particular shape and specific sound. Once more letters were taught, words that made sense were introduced. The children were early readers, so they read the words that made sense and words that did not make sense alike.

Generally, vowels were taught towards the beginning of the textbook, intermixed with the most common consonants. Diphthongs could be introduced within chapters or as separate chapters, once the second of the two letters was introduced. For example, in week 3 after the letters $\mathrm{m}$ (week 1) and k (week 3) were introduced, the diphthong "mk" was included within the lesson for "k". Analogies were generally introduced on the second page in the chapter. Analogies are letter blends of a consonant and a vowel, also known as syllables.

Although writing is not a part of the reading approach, the teachers wanted a review after every four letters. This review had a mix of letters previously taught as well as a page of writing practice. The Chichewa language has capital letters. Since capital letters were essentially new characters that were introduced, with similar sounds as their small case counterparts, they were added at the end of the book to avoid confusion. The introduction of a new capital letters took less time for the students to grasp as compared to the introduction of small case letters since, by then, children had become familiar with the pattern of learning letters and their associated sounds.

\section{Telangana, India}

Much time was spent deliberating how to apply cognitive-neuroscience principles summarized by Abadzi $(2013,2015)$ on teaching literacy to a Dravidian language and using a non-Latin script. Much consultation was sought from literacy experts and District education officials on how to include and teach secondary vowel and consonant forms and whether they should be paired with their primary letter forms for the sake of comparison. In many instances, secondary vowel forms appear more commonly than their primary vowel forms. However, teaching a secondary vowel form before introducing a primary vowel form did not conceptually make sense. Other symbols, such as halant and anuswara, differentiated the approach taken to applying this methodology in India versus other contexts. These symbols, when added to letters, are pronounced as half-letters. 
There was also deliberation on when and how to include writing as a task; for an alphasyllabic script such as Telugu, visually differentiating between letters could be complicated. The premise of deciding the order of letters to be taught was to introduce the most commonly used letters as early as possible in the supplemental book, rather than teaching in the traditional barakhadi/varnamala order. This way, common letters could be paired with each other to form meaningful words, so children could practice reading as early as possible. Learning the most frequent letters earlier enables them to read and recognize letters/words in their own settings earlier on. Thus, infrequently used letters were taught towards the end of the book content, irrespective of their order in the varnamala/barakhadi chart. Including these letters earlier on would not have helped students read familiar words, since they do not appear often; earlier introduction of these letters might have delayed students' progress in increasing reading speed with frequent letters.

\section{Generalized lessons for Early Literacy Approaches}

Some generalized observations based on the implementation research conducted as part of the study are discussed here. These observations could prove to be useful components of early literacy programs in low resourced settings.

The textbooks designed did not include large pictures. A small picture of the keyword is included to help the teacher remind students of the keyword, so they can associate it with the letter sound being taught. It is important to note the pictures of the keywords are the only pictures that appear in the textbook. The objective was to provide students a lot of practice reading words, photos took a lot of space which weren't necessarily helping children to decode words. Based on our classroom observations, early readers did not look at the picture and were concentrating on the letters they were trying to decode. The emphasis of this book is to have enough text in a large enough font for students to be able to have sufficient reading practice. The book is carefully formatted to not include pictures or waste a lot of blank space. The use of textbooks was limited to classroom use. After textbooks were used in the class, teachers preferred to keep them in the classroom itself. Teachers mentioned this reduced the wear and tear of textbooks and eliminated the chances of students forgetting the books at home. Teacher interviews revealed that students did not find time to go through these books at home.

Introduction of non-real words at the beginning of the book was under discussion. Linguists thought of this as a destruction of the language. However, the literacy experts thought of this exercise as a literacy acquisition exercise. At the beginning of the book, since many letters are not taught, there are limited words that can be formed. Non-real words would help in understanding the pattern of joining letters to form words that have a specific sound. Teachers are supposed to explain to students these are not real words but meant for practice, so that children do not hesitate to read them aloud. This is a transient phase, and soon children learn more letters and read words with meaning.

A few noteworthy features of this approach are that it does not require extensive training and preparation to conduct the routine in class. It has simple steps to follow with the workbook as the only teaching aid. Therefore, it saves time and funds that go into making Teaching Learning Materials (TLM). In a low-resource setting, where TLM and teacher training could be very expensive, learning initiatives that are cost-efficient have more chances of getting implemented with a good success rate in terms of learning outcomes. Learning approaches require the teacher to develop their own teaching aids, even if they are the teachers are local to the area they would still require additional time to plan and procure materials, which can be time intensive. Repeated, refresher teacher trainings are a source of budget drain (per diem and travels cost, etc.). In addition, teachers would need to stay away from their classes during training days. In many cases, schools run on fewer than adequate teachers, which adds to precious classroom time being wasted. In the past, printing expensive teacher manuals has not turned out to be useful to improve classroom observations. The approach does require ongoing classroom observations and supporting the teachers to be facilitators rather than conduct lectures in the classrooms. Reinforcement of teachers facilitating the class and giving ample time for students to do individual practice is a key component of this approach. Teachers act as facilitators to provide corrective feedback to students. Many literacy approaches require parents to follow-up on the child's reading skills at home. However, in the cases of Malawi and Telangana, it was difficult to get parents involved during school time, since they were busy with their daily chores. Parents were not familiar with what the children learnt at school and, because of their heavy day work, it was un-practical to get them involved in the classrooms.

Sequencing of letters in the textbook is based on a systematic frequency count. The textbook itself starts with one letter on each page in a larger font size. The textbook is first used to introduce single letters, leading to blending of letters to form words, and very quickly followed by teaching sentences. Languages such as Chichewa that have capital letters could add on capital letters at the end of the book to avoid children getting confused with the small case and capital letters that have the same sound. The capital letters could use capitalization of the first letter at the start of the sentences and for proper nouns. A list of proper nouns and names beginning with the letter being taught are listed, so students can get used to the types of words being capitalized and recognize common names and proper nouns with which they may be familiar.

Each language is slightly different in terms of its script. However, the approach works with transparent orthographies. Certain nuances had to be considered for each language. For instance, Chichewa had many conjugated words and it 
became very difficult for children to read long words; therefore, the project decided to break-up the words in small chunks. For Telugu, frequency counts of primary letter forms were conducted first and later, secondary vowel forms were added. Complex consonants were not included in the initial count of letters. Some infrequently used letters were left until the end of the book, and the most common vowels were taught earlier on. The sheer number of characters-- having two forms for each letter (primary and secondary)--as well as other symbols, such as halant and anuswara, differentiated the approach taken to applying this methodology in India versus other contexts.

Classroom management was particularly challenging during implementation of this approach. Children in Telangana schools were organized by grades, like any other school. However, an initial needs assessment pointed out that a child in grade 3 had similar learning challenges to a child in grade 1 . Therefore, children had to be specially organized for this learning program. Classes were organized to comprise all children from grades 1 - 3 who needed additional help in Telugu. Children in classrooms were organized based on their reading levels rather than based on their class. In Malawi, since the classes were held in the community, all learning levels of children and ages attended the class. The staff made groups based on learning levels.

The group of children who benefitted from this program were children who did not recognize letters and the associated sounds at baseline. The literacy approach was the most useful for children who started from learning letters and jumped to reading words. The children who already read words and needed more practice did not go to the next level of reading. There were children in Malawi who could read words but still joined these community classes. The teacher gave them additional reading materials to give them practice in reading. However, the textbook designed for this basic reading program was not useful for children who were already reading words. Children who were at the word level needed more text and practice than simply revising letters and combinations of letters. Comprehension is a byproduct of this approach. When children attain the 46 words per minute frequency, they retain the entire sentence structure and can make meaning. Therefore, comprehension was not added as a separate component of the program. Similarly, writing is not a focus of the program since the aim is to have children read as efficiently as possible.

A practice that would be useful as a follow-up to an early literacy program, such as the 100 days literacy project proposed here, is to put a library program in place so children do not forget newly acquired learning skills. African Story Books and StoryWeaver have hundreds of books in multiple languages that can be used immediately after early literacy intervention is complete.

The study presents contextualization of the cognitive-neuroscience principles in Telugu and Chichewa. The process that was followed to create the supplemental material and follow the classroom materials helps to understand the nuances of adaptation in various contexts. The study was able to highlight factors that are important in designing and implementing this reading approach in rural marginalized settings in India and Malawi. It helps to showcase how the approach could be customized to local languages in general and improve results in 100 days. Some of these generalized principles hold a lot of potential in improving student learning in a short amount of time, provided that classes are regular, teachers follow a simple routine, and the practice book is designed keeping cognitive-neuroscience principles in mind.

\section{References}

Abadzi, H. (2006). Efficient Learning for the Poor: Insights from the Frontier of Cognitive Neuroscience. Washington, DC: World Bank. (C) World Bank. https://doi.org/10.1596/978-0-8213-6688-2

Abadzi, H. (2013a). Literacy for all in 100 days? A research-based strategy for fast progress in low-income countries (English). Accessed from http://documents.worldbank.org/curated/en/docsearch/author/m93113

Abadzi, H. (2013b). Raising literacy from 20 percent to 80 percent? : A science-based strategy for GPE partner countries (English) Accessed from http://documents.worldbank.org/curated/en/docsearch/author/m93113.

Arai, J., Li, S., Hartley, D. M., \& Feig, L. A. (2009). Transgenerational Rescue of a Genetic Defect in Long-Term Potentiation and Memory Formation by Juvenile Enrichment. Neuroscience, 29(5), 1496-1502. https://doi.org/10.1523/JNEUROSCI.5057-08.2009

Baeten, M., Kyndt, E., Struyven, K., \& Dochy, F. (2010). Using student-centred learning environments to stimulate deep approaches to learning: Factors encouraging or discouraging their effectiveness. Educational Research Review, 5, 243-260. https://doi.org/10.1016/j.edurev.2010.06.001

Banerjee, A., Banerji, R., Berry, J., Duflo, E., Kannan, H., ... Walton, M. (2016). Mainstreaming an Effective Intervention: Evidence from Randomized Evaluations of "Teaching at the Right Level" in India. https://doi.org/10.3386/w22746

Bauman, J., Hoffman, J., Moon, J., \& Duffy-Hester, A. (1998). Here are teachers' voices in the phonics/*whole language debate? Results from a survey of U.S. elementary classroom teachers. Reading Teacher, 51(8), 636-650. 
Beatty, A., \& Pritchett, L (2012). From Schooling Goals to Learning Goals: How Fast. Can Student Learning Improve? CGD Policy Paper 012. Washington DC: Center for Global. Development. http://www.cgdev.org/content/publications/detail/1426531

Dehaene, S., \& Cohen, L. (2011). The unique role of the visual word form area in reading. Trends in Cognitive Sciences. May 16. [Epub ahead of print]. PMID 21592844. https://doi.org/10.1016/j.tics.2011.04.003

DeJongh, M. (2014). Best practices for developing supplementary reading materials. Executive Summary. USAID.

Feldon, D. F. (2007). Cognitive load and classroom teaching: The double-edged sword of automaticity. Educational Psychologist, 42 (3), 123-137. https://doi.org/10.1080/00461520701416173

Franceschini, S., Simone, G., Milena, R., Katia, P., \& Andrea, F. (2012). A Causal Link between Visual Spatial Attention and Reading Acquisition. Current Biology, (2012). https://doi.org/10.1016/j.cub.2012.03.013

Jukes, M., Dubeck, M., Wolf, S., et al. (2014) Testing to achieve Reading for All in Kenya. Paper presented at the Annual Conference of the Comparative and International Education Society, Toronto, Canada, March 14, 2014.

Karin, L., Dahl, K., \& Scharer, P. L. (2000). Phonics Teaching and Learning in Whole Language Classrooms: New Evidence from Research. The Reading Teacher, 5 (7), 584-594.

Lockheed, M., \& Harris, A. (2005). Beneath Education Production Functions: The Case of Primary Education in Jamaica. Peabody Journal of Education, 80(1), 6-28. https://doi.org/10.1207/S15327930pje8001_2

Marinelli, M., Martelli, M., Zocolotti, P., et al., (2012). Visual and linguistic factors in literacy acquisition: Instructional Implications For Beginning Readers in Low-Income Countries. Washington, DC: World Bank, GPE Working Paper Series on Learning no. 2

Pouezevara, S., Olala, B., \& Michael, C. (2012). Malawi National Early Grade Reading Assessment Survey. Accessed $19^{\text {th }}$ July 2017. https://ierc-publicfiles.s3.amazonaws.com/public/resources/Madagascar\%20national\%20EGRA.pdf

Seymour, P. H. K., Aro, M., \& Erskine, J. M. (2003). Foundation literacy acquisition in European orthographies. British Journal of Psychology, (94), 143-174. https://doi.org/10.1348/000712603321661859

UNESCO (2013/4). Teaching and Learning: Achieving quality for all. EFA Global Monitoring Report. UNESCO. Accessed 7 February, 2018http://unesdoc.unesco.org/images/0022/002256/225654e.pdf

UNESCO, (2013). Making Education a Priority in the Post 2015 Development Agenda. Paris, France. Accessed 7 February, 2018.

http://www.unesco.org/new/en/media-services/single-view/news/making_education_a_priority_in_the_post_2015_ development_agenda_new_report/\#.UjD5vaxnSSp

World Development Report (2018). Learning to Realize Education's Promise. The World Bank. Assessed 7Feb18. http://www.worldbank.org/en/publication/wdr2018

\section{Copyrights}

Copyright for this article is retained by the author(s), with first publication rights granted to the journal.

This is an open-access article distributed under the terms and conditions of the Creative Commons Attribution license which permits unrestricted use, distribution, and reproduction in any medium, provided the original work is properly cited. 